[Agr. Biol. Chem., Vol. 30, No. 5, p. 457 465, 1966]

\title{
Studies on the Cereal Starches
}

\author{
Part V Rheological Properties of the Starch \\ of Rices Imported into Japan \\ By Hisaya Horiuchi and Tatsuo TANI \\ Food Research Institute, Ministry of Agriculture and Forestry, Tokyo \\ Received November 12, 1965
}

\begin{abstract}
Twenty purified rice starches of domestic and imported rices from eight countries including indica and japonica subspecies were submitted to the test of the chemical compositions, pasting characteristics and dynamic visco-elasticity of cold paste body. High correlations were found between some of these characteristics in which were observed obvious differences among the samples. For characterization of rice starches, the samples were classified in 4 groups, according to the degree of these starch characters, which were roughly expressed as "Sticky type" and "Non-sticky or Flaky type"
\end{abstract}

\section{INTRODUCTION}

In recent years, the imports of rice from abroad have been decreasing in Japan according to the remarkable increase of domestic rice production, but the imported rice still plays an important role. Among the varieties of imported rices are included not only indica subspecies but also japonica ones. In general, Japanese consumers prefer a moist, sticky rice such as near waxy rice, differing mostly from rices now being consumed in the world. The problem of stickiness of cooked rice has offered a special interest in Japan. In relation to this subject, rheological studies of rice starch which is the most significant component in the grain have been carried out in our laboratory, in parallel with the various evaluation methods for the cooking and eating quality of rice grain.

During the course of the investigation of the rheological properties of rice starches with respect to regional effects of cultivation of domestic rice, ${ }^{1)}$ it has been found that rheological properties of rice starch are classified

1) H. Horiuchi, S. Chikubu and T. Tani, J. Agr. Chem. Soc. Japan, 35, 543 (1961). into two typical patterns, i.e., roughly expressing, "Sticky type" and "Non-sticky or Flaky type". The present paper has aimed to the rheological studies of stickiness of various kinds of imported rice starches, together with to confirm these patterns with extensive rice varieties.

\section{MATERIALS AND METHODS}

1. Rice. Ten varieties of rice (two samples per variety) were used in this study. These commercial samples consist of sixteen non-glutinous and two glutinous white rices imported in 1958 from seven countries; Thailand, Burma, Spain, Italy, Egypt, China mainland and Taiwan. In addition, two kinds of Japanese nonglutinous rices grown in 1957 were included among the samples. The details are shown in Table I. Cooking qualities of these samples have been previously determined by Chikubu et al.2)

2. Starch. Purified starches were prepared from these white rice powders by the procedure of soaking in $0.2 \%$ sodium hydroxide solution. Sedimented starch fraction was repeatedly soaked in the new alkaline solution until it gave no reaction of Biuret or Millon in the clear upper solution. Subsequently, the fraction was repeatedly washed with distilled

2) S. Chikubu, T. Iwasaki and T. Tani, Eiyû To Shokuryô, 13, 137 (1960). 


\section{TABLe I. Impurities OF THe Starch OF RICES IMPORTED INTO JAPAN}

\begin{tabular}{|c|c|c|c|}
\hline $\begin{array}{l}\text { Variety } \\
\text { indica long grain }\end{array}$ & Sample No.* & Ash content & Protein content \\
\hline Thailand & 1 & $0.11 \%$ & $0.34 \%$ \\
\hline$n$ & $1^{\prime}$ & 0.12 & 0.36 \\
\hline Burma (Ngasein-Japan, 15\%) & 2 & 0.09 & 0.37 \\
\hline$" \prime$ & $2^{\prime}$ & 0.09 & 0.34 \\
\hline Burma (Meedone-Japan, 15\%) & 3 & 0.10 & 0.23 \\
\hline$"$ & $3^{\prime}$ & 0.11 & 0.13 \\
\hline \multicolumn{4}{|l|}{ japonica short grain } \\
\hline Spain & 4 & 0.12 & 0.05 \\
\hline$"$ & $4^{\prime}$ & 0.12 & 0.05 \\
\hline Italy & 5 & 0.11 & 0.08 \\
\hline$n$ & $5^{\prime}$ & 0.12 & 0.08 \\
\hline Egypt & 6 & 0.11 & 0.04 \\
\hline$\pi$ & $6^{\prime}$ & 0.11 & 0.04 \\
\hline China mainland (Changshu) & 7 & 0.10 & 0.18 \\
\hline$"$ & $7 \prime$ & 0.10 & 0.12 \\
\hline Taiwan (Hôrai) & 8 & 0.08 & 0.08 \\
\hline$" \quad \prime$ & $8^{\prime}$ & 0.09 & 0.08 \\
\hline Japan (Ginmasari) & 9 & 0.11 & 0.08 \\
\hline$n \quad($ Kinmaze $)$ & $9^{\prime}$ & 0.09 & 0.09 \\
\hline \multicolumn{4}{|l|}{ Glutinous grain } \\
\hline Thailand & 10 & 0.06 & 0.05 \\
\hline$"$ & $10^{\prime}$ & 0.06 & 0.05 \\
\hline
\end{tabular}

* The samples marked with a "prime" are from another ship when imported.

water until rinsing water was no longer basic. Furthermore, large-size granules were removed from the starch slurry by means of repeated decantation in water, and the purified starch fraction was washed again, dehydrated with methyl alcohol and dried in d vacuum desiccator over sulphuric acid.

3. Amylose and Amylopectin. Amylose was fractionated with a 1:1 mixture of $n$-butyl and isoamyl alcohol3) from the starch which was defatted with $85 \%$ methyl alcohol for 16 hrs. It was twice recrystallized from the water saturated with $n$-butyl alcohol, and then dehydrated with butyl alcohol, and vacuum-dried at $70^{\circ} \mathrm{C}$.

Amylopectin was precipitated with methyl alcohol from the residual solution which was previously freed from amylose by use of cellulose chips, and dehydrated with methyl alcohol and ethyl ether successively.

4. Impurities. Residual nitrogen compound and ash contents of the purified starch were determined by usual methods.4)

3) E. J. Wilson, Jr., T. J. Schoch and C. S. Hudson, J. Am. Chem. Soc., 65, 1380 (1943).

4) American Association of Cereal Chemists, "Cereal Laboratory Methods", The Association, 1957, p. 42, 293.
5. Amylose Content. The starch defatted with 85\% methyl alcohol, amylose and amylopectin were first dried in a Abderhalden dryer over phosphorus pentoxide for $5 \mathrm{hrs}$. and heated with vapor of ethyl alcohol under reduced pressure below $1 \mathrm{~mm} \mathrm{Hg}$ to complete drying. The dried powder of $100 \mathrm{mg}$ of amylose, $100 \mathrm{mg}$ of starch and $250 \mathrm{mg}$ of amylopectin were taken exactly in microbeaker, respectively, and they were ground to fine powder with the $1 \mathrm{ml}$ of added alcohol. Subsequently the $15 \mathrm{ml}$ of $0.5 \mathrm{~N}$ potassium hydroxide solution was poured into the beakers. The liquid thus obtained was allowed to stand overnight and diluted to $100 \mathrm{ml}$ with distilled water. Ten milliliters of the dilute solution of amylose, $20 \mathrm{ml}$ of the solution of starch and amylopectin were poured into respective $100 \mathrm{ml}$ volumetric flasks, to which were subsequently added $10 \mathrm{ml}$ of $0.5 \mathrm{~N}$ potassium iodide and filled to $100 \mathrm{ml}$ with water. Fifty milliliters of the dilute solution was pipetted for the determination.

Amperometric determination was carried out using the technique of Kobayashi.5) For determination of 8, T8 Kobayashi and K. Yoshida, Denpun Kôgyô Gakkaishi, 
the current, the polarograph in which the applied voltage was taken as zero and the sensitivity was reduced to $1 / 100$ by means of a shunt, was used in conjunction with a rotating platinum electrode of Kolthoff A type at 750 r.p.m. and a saturated calomel electrode in a mantle beaker at $25^{\circ} \mathrm{C}$. The end point of the titration was obtained from a graph, the abscissa representing the volume of added $1 / 1000 \mathrm{~N}$ iodine solution and the ordinate, the galvanometer deflection. Amylose content was calculated according to the following $\left.\mathrm{Eq} .{ }^{6}\right)$ from the obtained iodine affinity (amylose iodine binding).

$$
\text { Amylose } \%=(S-B) \times 100 /(A-B)
$$

Where, $A, B$ and $S$ represent the iodine affinity of amylose, amylopectin and starch respectively.

6. Amylography. The standard model Brabender Amylograph (ASG-1 type, The Brabender Corp., Duisburg, Ger.) was used. The procedure was described previously.1) In amylograph bowl, $500 \mathrm{~g}$ of $7.3 \%$ starch slurry was heated from 30 to $93^{\circ} \mathrm{C}$, immediately followed by cooling back to $30^{\circ} \mathrm{C}$ at the rate of $1.5^{\circ} \mathrm{C}$ per min.

7. Alkali-viscography. A viscography based on increasing alkali normality was carried out using a method virtually identical with that of Suzuki, 7 ) but the present authors used a small motor-driven stirrer. Therefore, a nearly constant stirring may be given though some viscosity lowering due to agitation is not avoidable. Viscosity was determined by means of Brookfield type viscometer at the stationary state. To $300 \mathrm{~g}$ of $2.5 \%$ starch slurry which was $0.2 \mathrm{~N}$ alkaline at the beginning, $5 \mathrm{~N}$ potassium hydroxide solution was added slowly so as to increase alkalinity by $0.01 \mathrm{~N}$ during each successive $5 \mathrm{~min}$. period.

8. Dynamic Visco-elasticity. Top-drive coaxial rheometer (FT type) designed by Takenaka ${ }^{8}$ ) was used (Fig. 1). After preparation using the amylograph, the starch paste was put in the gap between the coaxial internal and fixed external cylinders at $10^{\circ} \mathrm{C}$; then it was allowed to stand for an hour. At the top of the suspension wire $k$, a sinusoidal rotational oscillation was applied and the movement of the internal cylinder was recorded on a photographic plate as a Lissajous' figure obtained by combining perpendicularly the oscillation of the internal cylin-

6) S. Kawamura and M. Tada, J. Agr. Chem. Soc. Japan, 33, 296 (1959).

7) H. Suzuki and N. Taketomi, Kogyô Kagaku Zasshi, 59, 45 (1956).

8) H. Takenaka and Y. Ogawa, Kobunshi Kagaku, 18, 374 (1961).

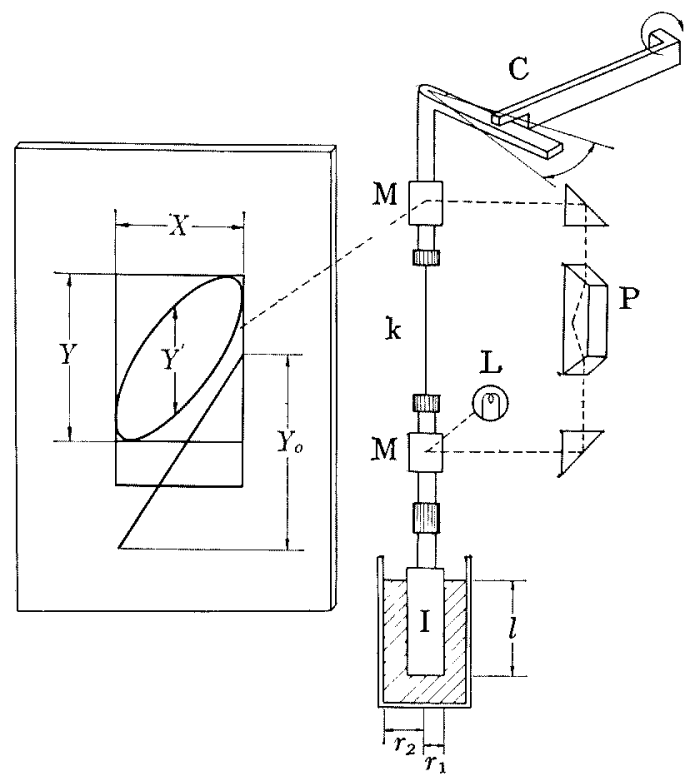

FIG. 1. Schema of FT-Rheometer.

$C$, crank mechaniam; $I$, internal cylinder; $k$, wire, $L$, pin-hole light; $M$, mirror; $P$, prism.

der and the oscillation at the top of the wire. Periods of the movement was varied by 5 steps from $600 \mathrm{sec}$. to $0.5 \mathrm{sec}$. and the Lissajous' figures were obtained at the stationary states in each case. Typical Lissajous' figure is shown in Fig. 1.

The dynamic viscosity $\gamma$ and the dynamic rigidity $G$ were calculated by following Eqs.;

$$
\begin{aligned}
\eta & =B_{0} k A \sin \phi / \omega & & \text { (poise) } \\
G & =B_{0} k(A \cos \phi-1)+I_{\omega^{2}} & & \text { (dyn. } \left./ \mathrm{cm}^{2}\right)
\end{aligned}
$$

where, $B_{0}$ was the quantities concerning the geometry of the sample.

$$
B_{0}=1 / 4 \pi l \cdot\left(1 / r_{1}{ }^{2}-1 / r_{2}{ }^{2}\right)
$$

The phase angle $\phi\left(\sin \phi=Y^{\prime} / Y\right)$ and the amplitude ratio $A\left(A=Y_{0} / Y\right)$ were obtained by the analysis of the picture and the torsion constant of the wire $k$, the radius of the internal cylinder $r_{1}$ and that of the external cylinder $r_{2}$ were determined previously. $\omega$ was the angular frequency and $l$ was the depth of the immersion of the internal cylinder. The experimental details are as follows:

$$
\begin{gathered}
r_{1}=1.50 \mathrm{~cm}, r_{2}=1.79 \mathrm{~cm}, l=8.15 \sim 9.46 \mathrm{~cm}, \\
k=9.68 \times 10^{4} \sim 3.0 \times 10^{6} \mathrm{dyn} . \cdot \mathrm{cm} .
\end{gathered}
$$


At $10^{\circ} \mathrm{C}, 7.3 \%$ rice starch paste formed a gel. In order to prevent slipping of starch paste against internal cylinder, vinyl lacquer was coated on the surface of the cylinder and coarse pattern was printed on the surface by pressing a gauze before drying.

As a standard viscous matter, $60 \%$ cane sugar solution and pure glycerol were tried and no rigidity was found.

\section{RESULTS AND DISCUSSION}

1. Impurities of Starch Granules. Residual protein and ash contents in various kinds of foreign rice starch are shown in Table $I$. Ash content of each sample shows the same $0.1 \%$ level except a low value for the glutinous one of Thailand. Protein content is found to be considerablly different among samples. Samples from Thailand and Burma, i.e,. indica rice starches prove to have especially high protein content of $0.3 \%$, but the ones from Spain, Italy, Egypt, Taiwan and Japan, i.e., japonica rice starches are found to have very low values except slightly high value of the one from China mainland. For the latters, the values from 0.04 to $0.09 \%$ are obtained. It was observed beforehand that no protein reaction was detected in the alkaline steep liquor of indica rice starches; nevertheless, the above-obtained protein values for the starch itself are higher than that of wheat starch which was prepared without using alkaline solution. Therefore, it seems that the purity of indica rice starches is lower than that of japonica varieties, and that it is difficult to reduce protein content of indica rice starches below that of japonica varieties, owing to their compact granular structure. It is thought that the protein content of starch is one of the characteristic values representing the quality of rice, and much attention should be paid on it.

Table II. Determination of Amylose Content by AMPerometry

\begin{tabular}{|c|c|c|c|c|c|c|}
\hline \multirow[b]{2}{*}{ Variety } & \multirow[b]{2}{*}{ Sample No. } & \multicolumn{3}{|c|}{ Iodine affinity } & \multicolumn{2}{|c|}{ Amylose content } \\
\hline & & $\begin{array}{c}\text { Amylose } \\
A\end{array}$ & Amylopectin & $\begin{array}{c}\text { Starch } \\
S\end{array}$ & $(S-B) /(A-B)$ & $S / 18.3^{*}$ \\
\hline Thailand & 1 & $15.1 \%$ & $0 \%$ & $4.70 \%$ & $31.2 \%$ & $25.7 \%$ \\
\hline$"$ & $1^{\prime}$ & & & 4.51 & 29.9 & 24.6 \\
\hline Burma (Ngasein) & 2 & 13.5 & 1.14 & 4.45 & 26.8 & 24.3 \\
\hline$" \prime$ & $2^{\prime}$ & & & 4.57 & 27.8 & 25.0 \\
\hline Burma (Meedone) & 3 & 14.5 & 0.33 & 3.96 & 25.7 & 21.6 \\
\hline$"$ & $3^{\prime}$ & & & 3.96 & 25.7 & 21.6 \\
\hline Spain & 4 & 17.8 & 0.20 & 3.34 & 17.8 & 18.3 \\
\hline$n$ & $4^{\prime}$ & & & 3.21 & 17.1 & 17.5 \\
\hline Italy & 5 & 17.1 & 0.45 & 3.52 & 18.5 & 19.2 \\
\hline$"$ & $5^{\prime}$ & & & 3.77 & 20.0 & 20.6 \\
\hline Egypt & 6 & 17.2 & 0.17 & 3.46 & 19.3 & 18.9 \\
\hline$"$ & $6^{\prime}$ & & & 3.15 & 17.5 & 17.2 \\
\hline China mainland & 7 & 15.8 & 0.79 & 3.83 & 20.2 & 20.9 \\
\hline$"$ & $7^{\prime}$ & & & 3.46 & 17.8 & 18.9 \\
\hline Taiwan & 8 & 18.1 & 0.11 & 3.21 & 17.3 & 17.5 \\
\hline$"$ & $8^{\prime}$ & & & 3.21 & 17.3 & 17.5 \\
\hline Japan & 9 & 17.8 & 0.28 & 3.58 & 18.8 & 19.6 \\
\hline " & $9^{\prime}$ & & & 3.89 & 20.6 & 21.3 \\
\hline Glutinous** & 10 & 12.4 & 0.03 & 0.37 & 2.8 & 2.0 \\
\hline " & $10^{\prime}$ & & & 0.25 & 1.8 & 1.4 \\
\hline
\end{tabular}

* Iodine affinity of potato amylose. ${ }^{5}$ )

** Grown in Thailand. 
2. Amylose Content. The amylose content of rice starches by the amperometry is given in Table II. The results show fairly large differences among samples as to the iodine affinity of the starches $(S)$. As a whole, indica varieties show large values as to the iodine affinity of the starches $(S)$ but slightly small values as to that of the amylose $(A)$. It is generally considered that indica varieties contain much long chain fraction. But the present Table shows that the chain length of the amylose fraction is comparatively short, because iodine affinity is supposed to be a measure of chain length. It is supposed that tha fact was owing to the long chain fraction of the indica varieties was difficult to be dissolved at the fractionation. To improve on the point, the values in the last column of the Table are ones calculated using the iodine affinity of potato amylose $\left(18.3 \%{ }^{51}\right)$.
In addition, the determination of amylose content was carried out by means of colorimetry in perchloric acid solution described by $\mathrm{McCready}^{9}$ ' with all the samples. The trend of differences observed among the samples agreed with the results of amperometry, though the colorimetric results showed higher level. Consequently, it seems that the trend of differences can be taken as a reliable result. Such a high amylose content of 26 to $31 \%$ on rice starch has been seldom found in any previous reports, but the recent report by Juliano $^{101}$ presented the coincidental data on the rices in the Southeast Asia.

While the glutinous species of Thailand is determined to have about $2 \%$ amylose content which seems to be slightly higher as regards waxy seed, though there was a report ${ }^{10)}$ with higher values about it.

3. Amylographic Characteristics. Table III

Table III. Amylographic Characteristics of the Starch of Imported Rices

\begin{tabular}{|c|c|c|c|c|c|c|}
\hline Variety & $\begin{array}{c}\text { Sample } \\
\text { No. }\end{array}$ & Pasting temp. & Max. viscosity & Breakdown & Consistency & $\begin{array}{l}\text { Breakdown/ } \\
\text { consistency }\end{array}$ \\
\hline Thailand & 1 & $72{ }^{\circ} \mathrm{C}$ & 565 B.U. & 200 B.U. & 535B.U. & 0.37 \\
\hline " & $1^{\prime}$ & 70.5 & 705 & 285 & 595 & 0.48 \\
\hline Burma (Ngasein) & 2 & 73.5 & 460 & 145 & 405 & 0.36 \\
\hline$"$ & $2^{\prime}$ & 73.5 & 655 & 175 & 620 & 0.28 \\
\hline Burma (Meedone) & 3 & 70 & 495 & 190 & 465 & 0.41 \\
\hline$" \quad "$ & $3^{\prime}$ & 69.5 & 815 & 425 & 480 & 0.89 \\
\hline Spain & 4 & 63 & 645 & 315 & 565 & 0.56 \\
\hline$"$ & $4^{\prime}$ & 65.5 & 710 & 375 & 445 & 0.84 \\
\hline Italy & 5 & 61.5 & 425 & 140 & 525 & 0.27 \\
\hline$"$ & $5^{\prime}$ & 62.5 & 375 & 110 & 525 & 0.27 \\
\hline Egypt & 6 & 64.5 & 570 & 260 & 735 & 0.35 \\
\hline$\pi$ & $6^{\prime}$ & 67 & 535 & 190 & 375 & 0.51 \\
\hline China mainland & 7 & 63 & 490 & 170 & 550 & 0.31 \\
\hline " & $7 \prime$ & 62 & 510 & 185 & 590 & 0.31 \\
\hline Taiwan & 8 & 66 & 550 & 245 & 435 & 0.56 \\
\hline$"$ & $8^{\prime}$ & 65 & 655 & 290 & 420 & 0.69 \\
\hline Japan & 9 & 63 & 580 & 280 & 775 & 0.36 \\
\hline$"$ & $9^{\prime}$ & 59 & 470 & 170 & 520 & 0.33 \\
\hline Glutinous* & 10 & 63 & 820 & 370 & 190 & 1.95 \\
\hline$n$ & $10^{\prime}$ & 63 & 805 & 360 & 190 & 1.89 \\
\hline
\end{tabular}

* Grown in Thailand.

9) R.M. McCready and W.Z. Hassid, J. Am. Chem. Soc., 65, 1154 (1943). 
shows the characteristic values of the amylogram. ${ }^{11)}$ Every indica rice starch shows the value higher than $70^{\circ} \mathrm{C}$ as to Brabender pasting temperature. These values apparently differ from those of japonica rice starches, though there are slight differences between samples of respective variety. Although maximum viscosity or peak viscosity vary from 375 to 820 B.U. among the samples, no relationship to the varieties is observed differing from the case of the other properties such as amylose content, residual protein content and so on. Breakdown (maximum viscosity minus minimum viscosity) shows in almost the same trend as in maximum viscosity. The value of consistency or set-back on cooling is as fairly high as maximum viscosity except for a lower value of glutinous species of Thailand. Furthermore, related characteristics, e.g., ratio of breakdown to consistency shows apparent differences among the samples and it also shows a high correlation with rigidity of paste which will be mentioned in the later section (6).

4. Alkali-Viscogram. The characteristic values of alkali-viscogram for all samples are shown in Table IV The concentration of potassium hydroxide at the gelatinization give more pronounced differences among the varieties than in the Brabender pasting temperature, and indica rice starches is observed higher values than in japonica rice starches. But it is noted that the latter varieties are divided into two definite groups, of either $0.3_{\mathrm{N}}$ or about $0.2 \mathrm{~N}$. These results give a trend similar to the case of the reaction of rice grain to treatment with dilute alkali ("alkali test" ") ${ }^{12)}$ when the same white rices as in this report were tested, ${ }^{2)}$ and consequently it appears that "alkali test" is dependent on the

Table IV. Characteristics on Alkali-Viscogram of the Starch of Imported RiCes

\begin{tabular}{|c|c|c|c|c|}
\hline Variety & Sample No. & Geltatinization $\mathrm{KOH} \mathrm{N}^{*}$ & Max. viscosity & $\mathrm{KOH} \mathrm{N}$ at max. viscosity \\
\hline Thailand & 1 & $0.36 \mathrm{~N}$ & $300 \mathrm{cp}$ & $0.40 \mathrm{~N}$ \\
\hline$"$ & $1^{\prime}$ & 0.36 & 375 & 0.42 \\
\hline Burma (Ngasein) & 2 & 0.38 & 255 & 0.42 \\
\hline$n$ & $2^{\prime}$ & 0.37 & 410 & 0.41 \\
\hline Burma (Meedone) & 3 & 0.33 & 250 & 0.36 \\
\hline$"$ & $3^{\prime}$ & 0.36 & 255 & 0.42 \\
\hline Spain & 4 & 0.30 & 420 & 0.33 \\
\hline$"$ & $4^{\prime}$ & 0.31 & 230 & 0.35 \\
\hline Italy & 5 & 0.24 & 250 & 0.26 \\
\hline$"$ & $5^{\prime}$ & 0.22 & 355 & 0.27 \\
\hline Egypt & 6 & 0.31 & 255 & 0.34 \\
\hline$"$ & $6^{\prime}$ & 0.31 & 230 & 0.34 \\
\hline China mainland & 7 & 0.25 & 310 & 0.27 \\
\hline$n$ & $7 \prime$ & 0.24 & 230 & 0.29 \\
\hline Taiwan & 8 & 0.31 & 190 & 0.35 \\
\hline$n$ & $8^{\prime}$ & 0.31 & 150 & 0.38 \\
\hline Japan & 9 & 0.27 & 170 & 0.30 \\
\hline$n$ & $9^{\prime}$ & 0.22 & 355 & 0.25 \\
\hline Glutinous** & 10 & 0.31 & - & - \\
\hline $\begin{array}{l}\text { " } \\
\text { * The value at } 50 \\
\text { ** Grown in Thaila }\end{array}$ & $10^{\prime}$ & 0.32 & - & - \\
\hline
\end{tabular}

11) E. G. Mazurs, T. J. Schoch and F.E. Kite, ibid., 34, 141 (1957).
12) R. R. Little, G.B. Hilder and E.H. Dawson, Cereal Chem., 35, 111 (1958). 
resistance of starch. Kihara ${ }^{13)}$ and Kurasawa ${ }^{14)}$ have observed no relation between the result of "alkali test" and the concentration of potassium hydroxide at the gelatinization as regards Japanese rices. It may, however, be stated that some ambiguous point for the relation between the "alkali test" and alkaliviscography has been made clear, since the varieties of very wide range of the degree of swelling are used in the present study.

Maximum viscosity on alkali-viscogram give no noticeable difference among the samples except for a particularly high value on the glutinous rice of Thailand. No significant meaning will be drawn out from such an extent of difference as shown in Table IV. because in this procedure constant stirring as in Brabender amylograph is not practised.

5. Mechanical Behavior of Cold Paste Body. Frequency dependence of the dynamic viscosity and rigidity of each variety is shown in Fig. 2. The dynamic viscosity decreases markedly with the increase of angular frequency $\omega$-the decrease of period $T$, and the dynamic rigidity increases slightly on the other hand. Nakagaki ${ }^{15}$ ) has observed an unusual change of viscosity and rigidity of rice starch paste at about $\omega=10$. Such an effect is not observed in the present experiment. Rigidity of the samples from Burma (Ngasein) and Thailand increases remarkably with the increase of angular frequency. Large $\eta$ and $G$ of the samples from Thailand, Burma (Ngasein and Meedone), Italy and China mainland in contrast to small $\eta$ and $G$ of the ones from Egypt, Spain, Taiwan and Japan is quite obvious. Rigidity of the glutinous rice of Thailand is considerably smaller than that of the non-glutinous varieties, but is larger than that of the glutinous species of Japan. ${ }^{16)}$

13) Y. Kihara, Y. Kajikawa and M. Gosho, Nôsan Kakô Gijutsu Kenkŷ́ Kaishi, 8, 263 (1961).

14) H. Kurasawa, I. Igaue and T. Hayakawa, $J . A g r$. Chem. Soc. Japan, 38, 173 (1964).

15) M. Nakagaki and K. Muragishi, Bull. Chem. Soc. Japan, 34, 316 (1961)

16) S. Chikubu, H. Horiuchi and T. Tani, J. Agr. Chem. Soc. Japan, 31, 397 (1957).

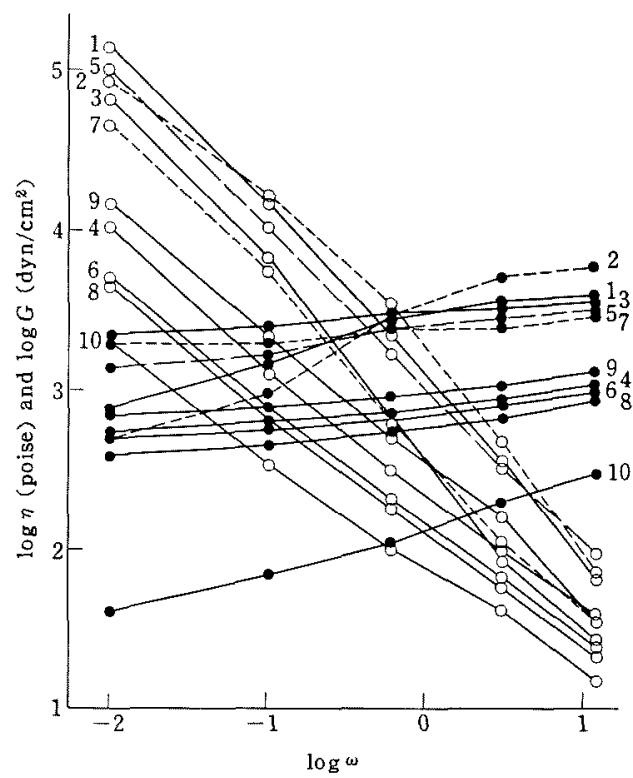

FIG. 2. Frequency Dependence of Dynamic ViscoElasticity.

$\eta(O)$ and $G(0)$ of $7.3 \%$ cold paste body. The figures are sample number.

\begin{tabular}{cl} 
Sample number & \multicolumn{1}{c}{ Variety } \\
1 & Thailand \\
2 & Burma (Ngasein) \\
3 & Burma (Meedone) \\
4 & Spain \\
5 & Italy \\
6 & Egypt \\
7 & China mainland \\
8 & Taiwan \\
9 & Japan \\
10 & Thailand (Glutinous)
\end{tabular}

For analysing the differences of visco-elasticity among the samples and their frequency dependence, four-element mechanical model was used with average experimental values of three groups above-mentioned. But the curves of frequency effect calculated from the obtained parameters did not coincide with the experimental curves. Similarly, Nakagaki ${ }^{15)}$ reported that the dynamic viscoelasticity of starch paste could not be explained by the four-element model. While Sterling ${ }^{17}$ ) suggested based on creep experiments the mechanical model which includes a thixotropic element. From these results, 17) C. Sterling, Food Research, 21, 491 (1952). 
it is considered that the mechanical behavior of stach gel is not so simple as is interpreted by the linear model.

6. Correlation between the Significant Properties. Fairly close relations are found among some significant properties as mentioned above, when compared with respect to those trends of differences among the samples. By way of example, there are close correlations between the Brabender pasting temperature and gelatinization normality of potassium hydroxide on the alkali-viscogram (correlation coefficient, $r=0.89^{* *}$ ), or between maximum viscosity on the amylogram and rigidity of the paste (at $\omega=0.628$ or $T=10 \mathrm{sec}$.) $\left(r=-0.62^{* *}\right)$. With the exception of glutinous variety, which hardly resembles non-glutinous varieties in various points, similar high correlations are also found between several other properties, i.e., between amylose content and residual protein content $\left(r=0.91^{* *}\right)$, between maximum viscosity and the ratio of breakdown to consistency $\left(r=0.77^{* *}\right)$, or between rigidity and amylose content $\left(r=0.67^{* *}\right)$, and also between rigidity and the ratio of breakdown to consistency $\left(r=-0.65^{* *}\right)$. Similarly, Juliano $0^{10)}$ observed high correlations between amylose content and setback value or final viscosity of amylogram.

From the observation of these correlations, it is supposed that the gelatinization either by heat or by alkaline solution is caused by the collapse of the microgranular structure ${ }^{187}$ that leads to the swelling of starch granules; furthermore, the rheological behavior of hot or cold paste body is also in close relation with the granular structure of starch that are affected by not only amylose but also residual protein. It appears that the residual protein in starch granules plays a role in the formation of starch granules themselves, and that it is just as important as amylose in the
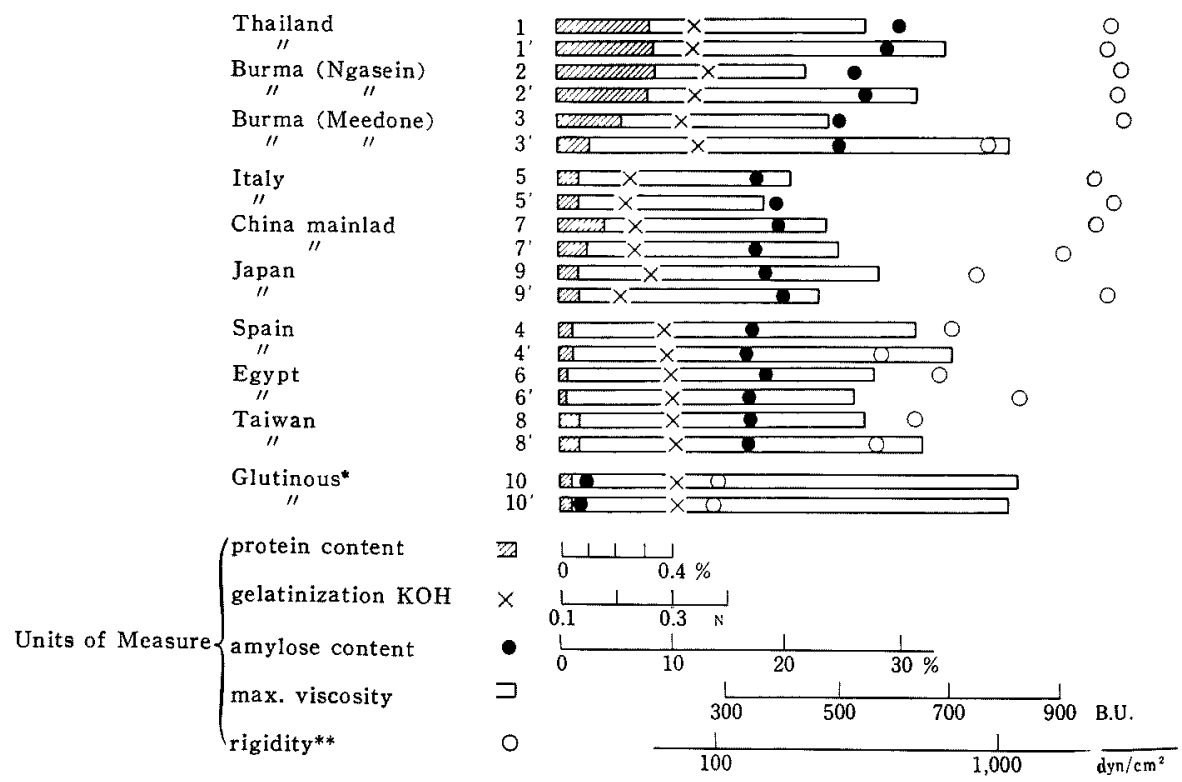

FIG. 3. Some Significant Starch Properties of Various Imported Rices.

* Grown in Thailand, ** The value at $\omega=0.628(T=10 \mathrm{sec}$. $)$

18) Z. Nikuni, J. Agr. Chem. Soc. Japan, 30, A 131 (1956)- 
granules with respect to the viscosity of paste.

7. Characterization of Rice Starches. These high correlations and obvious differences of the starch properties among the samples are expressed in Fig. 3. Among these properties, rigidity, residual protein and amylose content are observed to have almost the same tendencies. According to the magnitude of these properties it is possible to group them, to indicate by the source, in the following order:

(I) Thailand, Burma (Ngasein and Meedone) $>$ (II) Italy, China mainland, Japan, Egypt, Spain, Taiwan $>$ (III) Thailand (glutinous) In the case of maximum viscosity or the ratio of breakdown to consistency, there appears reverse order. On the other hand, pasting temperature and alkali normality at gelatinization show the tendency different from such characteristics as rigidity, residual protein and amylose content:

(I) indica varieties $>$ (III) Glutinous species of Thailand $>$ (II) Species of Egypt, Spain, Taiwan $>\left(\mathrm{II}^{\prime}\right)$ Species of Italy, China mainland, Japan

The japonica varieties are divided into two groups as above.

In view of the above considerations, it is assumed that high-amylose starch has compact granule structure, consequently it is difficult to remove the impurities, and to swell, and that high rigidity in paste is general in all rice starches including non-glutinous and glutinous of both indica or japonica subspecies. Therefore, to summarize, the starch having low maximum amylogram viscosity, high rigidity, high amylose content, high residual protein content, and high resistance to alkaline solution is "Non sticky type" or "Flaky type" and the starch of the opposite tendency is "Sticky type" It may be concluded that "Stickiness" tends to increase in the downward direction in Fig. 3. It would be permissible to state that the above-mentioned methods will be applicable to the evaluation or characterization of rices.

Acknowledgment. The authors express thank to Dr. T. Nakagawa, Professor of Hokkaido University, for his constant guidance on the rheological study, and to Dr. Z. Nikuni, President of The Institute of Scientific and Industrial Research, Osaka University, and Dr. T. Kobayashi, Professor of Tokyo University of Agriculture and Technology for their kind advices on the amylose content determination. The authors also thank Dr. $\mathrm{S}$. Chikubu of this laboratory for many helpful discussions and Miss. C. Saito for her assistance in the experimental work. 